\title{
Does Preoperative Anemia Deteriorate Patients' Postoperative Outcome or about the Difficulty of Comprehension
}

Sirilak Suksompong and Benno von Bormann*

Department of Anesthesiology, Siriraj Hospital, Mahidol-University, Bangkok 10700, Thailand

\begin{abstract}
The effect of red cell transfusion is frequently overrated, probably because decision makers are not always familiar with oxygen physiology. Even halving the hemoglobin does not lead to a critical shortage of oxygen supply for the tissues, as long as circulation is normal.

However, preoperative anemia is proven to be correlated to deterioration of surgical patients' outcome. The reason for this is debatable, and most scientists estimate anemia as a surrogate parameter for patients' general condition and co-morbidity.

There are several studies regarding anemia and red cell transfusion within the huge database from the American College of Surgeons National Surgical Quality Improvement Program, these studies often apply highly sophisticated statistical approaches. Some studies found that preoperative anemia is independently associated with an increased risk of postoperative mortality and morbidity, but this is not confirmed by other researchers, despite using the identical data source. Therefore, up to now there is no conclusive evidence that preoperative anemia exclusively influences the outcome of surgical patients.

The average reader of scientific literature cannot always cope with the complicated statistical methods employed, thus being unable to comprehend the message of a publication. To make it even worse, highly ranked statisticians estimate up to $90 \%$ of medical studies to be biased and claim that unreliable data are the rule in medical literature.
\end{abstract}

The more sophisticated research methods are applied, the more comprehensibility is needed for publishing results, following the suggestion of Leonardo da Vinci, "Simplicity is the ultimate sophistication".

Keywords: Anemia deteriorate patients; Postoperative outcome

\section{Physiology of Red Cell Transfusion; Hopes and Reality}

Red cells are given to improve oxygenation of the tissues. The oxygen supply of a normal, cardiopulmonary stable adult individual with hemoglobin concentration $(\mathrm{cHb})$ of $15 \mathrm{~g} / \mathrm{dl}$ corresponding with an oxygen-concentration of $21 \mathrm{ml} / \mathrm{dl}$ is about $1,000 \mathrm{ml} / \mathrm{min}$, whereas the-utilization (consumption) is $200-250 \mathrm{ml} / \mathrm{min}$ [1]. Ergo the available oxygen (supply) exceeds the demand (consumption) about four- to fivefold. As demonstrated in Table 1, an anemia with $\mathrm{cHb} 7.5 \mathrm{~g} / \mathrm{dl}$ does not even nearly jeopardize oxygen supply as long as blood circulation is adequate.

The ability of compensating anemia by increasing cardiac output and/or oxygen extraction rate in normovolemic mammals has been extensively investigated [2,3] finding its clinical equivalent in the successful treatment of Jehovah's witnesses [4-6].

The rationale for transfusing red cells seems to be often emotional instead of evidence based. In a prospective study Senay and coworkers evaluated 1,854 non-transfused cardiosurgical patients asking provocatively [7]. 'Is it the patient or the physician who cannot tolerate anemia?' They investigated two groups regarding to the lowest (nadir) hematocrit during bypass, either $<21 \%(n=174)$ or $>21 \%(n=1,680)$.

\begin{tabular}{|c|c|c|c|}
\hline $\begin{array}{c}\mathbf{c H b}(\mathbf{g} / \mathbf{d l}) \\
\text { in rest (ml/min) }\end{array}$ & $\mathbf{O}_{2}$-content (ml/dl) & $\begin{array}{c}\mathbf{O}_{2} \text {-supply } \\
(\mathbf{m l} / \mathbf{m i n})\end{array}$ & $\mathbf{O}_{2}$-consumption \\
\hline 15 & 21 & 1,000 & \multirow{2}{*}{$200-250$} \\
\hline 10 & 14 & 700 & \\
\hline 7.5 & 11.5 & 550 & \\
\hline
\end{tabular}

Table 1: Oxygen supply as a function of hemoglobin concentration $(\mathrm{cHb})$ and oxygen content under physiologic conditions $\left(\mathrm{O}_{2}\right.$-Saturation $99-100 \%$; cardiac output $\sim 5 \mathrm{l} / \mathrm{min}$ ) in an adult individual.
Mortality rate was $0 \%$ and $1 \%$ respectively. The authors concluded, 'it's the physician who cannot tolerate anemia. Representative for others with similar results Bennet-Guerrero et al. reported about variations of transfusion practice in the US [8]. They investigated the data of 102,470 patients with coronary artery bypass graft (CABG) from 798 hospitals. Between otherwise comparable groups of patients the rates of red cell transfusion ranged from 7.8 to $92.8 \%$.

For many years there have been data from physiologic studies demonstrating that red cell transfusion in hemorrhagic or septic volume-resuscitated patients with 'moderate to severe' anemia has no effect on microcirculation and oxygen consumption [3,9]. Sadaka et al. performed a prospective observational study in patients with severe sepsis and initial $\mathrm{cHb}$ of $7.23 \mathrm{~g} / \mathrm{dl}$ and serum lactate of $4.1 \mathrm{mmol} / \mathrm{l}$ [10]. One hour after transfusing red cells thereby elevating the $\mathrm{cHb}$ approx. $20 \%$ there was no change in tissue oxygenation or lactate levels as shown in Figure 1. Robertson and Bennet-Guerrero reviewed the impact of transfused erythrocytes on global and regional oxygenation

*Corresponding author: Benno von Bormann, Department of Anesthesiology, Siriraj Hospital, Mahidol-University, 2 Prannok Road, Bangkoknoi, Bangkok 10700, Thailand, Tel: 00660 24197990; Fax: 0066 0 24113256; E-mail: bvb@jodu.de

Received March 04, 2014; Accepted March 24, 2014; Published March 29 , 2014

Citation: Suksompong S, Bormann BV (2014) Does Preoperative Anemia Deteriorate Patients' Postoperative Outcome or about the Difficulty of Comprehension. J Blood Disorders Transf 5: 205. doi: 10.4172/2155-9864.1000205

Copyright: (c) 2014 Suksompong S, et al. This is an open-access article distributed under the terms of the Creative Commons Attribution License, which permits unrestricted use, distribution, and reproduction in any medium, provided the original author and source are credited. 
Change (\%) $1 \mathrm{~h}$ after PRC transfusion. Initial $\mathrm{cHb} 7.23 \mathrm{~g} / \mathrm{dl}$

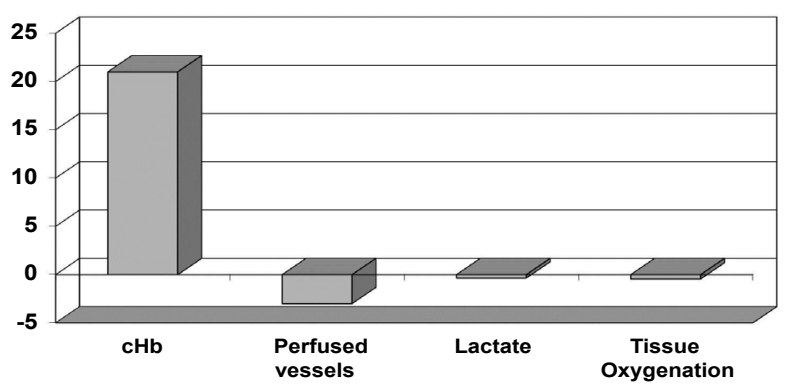

Figure 1: Influence of red cell transfusion on microcirculation and tissue oxygenation [10].

[1]. They defined a $\mathrm{cHb}$ of $7.0 \mathrm{~g} / \mathrm{dl}$ as 'moderate anemia' being safe in patients without severe cardiac dysfunction. They also emphasized that the hemoglobin concentration ( $\mathrm{cHb}$ ), particularly in hemorrhagic shock can only be applied as transfusion trigger after consideration of the patients volume status.

It is obvious that physicians frequently overestimate the effect of red cell transfusion.

\section{Red cell (RC) Transfusion and Outcome}

There is evidence that homologous (allogeneic) blood transfusion impairs outcome in surgical patients [11-14]. In the severely ill most studies reported that the risks of RC-transfusion outweigh the benefit [15]. The deterioration of outcome after red cell transfusion is not alone related to the general risk of the patient. Paone and coworkers have recently investigated 31,818 CABG patients divided into four groups with low, moderate, medium, and high risk [16]. In all four groups the effect of transfusion was qualitatively similar, transfusion leading to significant increase in postoperative morbidity and mortality.

The multicenter study of Ferraris et al. [11] in non-cardiac surgical patients compared about 15,000 patients receiving a single unit of homologous red cells to nearly 900,000 non-transfused patients. Patients with no transfusion had a significant better outcome (mortality, wound healing, pneumonia and sepsis morbidity). Murphy et al. in a single center retrospective analysis of propensity matched groups of CABG patients (transfused vs. non-transfused) found out that red cell transfusion was an independent predictor of mortality, infectious and ischemic morbidity and length of hospital stay (LOS) [13]. Interestingly, nadir (lowest) hematocrit during Extracorporeal Circulation (ECC), even $<21 \%$ had no influence on outcome data.

The currently available evidence clearly indicates that red cell transfusion is independently associated with deterioration of postoperative outcome in surgical patients. The pathophysiology of this dysfunction is unknown yet, though there are suggestions that transfusions may induce a shift of the immunologic environment $[17,18]$. We believe future studies have to focus on red cell transfusion and its impact on immune modulation.

\section{Permissive Anemia}

Against the background of the available data, as well as the success of bloodless surgery, great efforts were made to avoid red cell transfusions; including permissive anemia by applying restrictive transfusion triggers
[6]. The first large randomized study comparing restrictive $(\mathrm{cHb}<7.0 \mathrm{~g} /$ dl) with liberal $(\mathrm{cHb}<10.0 \mathrm{~g} / \mathrm{dl})$ transfusion regimen in anemic $(\mathrm{cHb}$ $\leq 9.0 \mathrm{~g} / \mathrm{dl}$ ) normovolemic critically ill patients was conducted by the Canadian group of Hébert et al. [19]. They reported that the outcome in the restrictive group was even better compared to the liberal group. Their data have been frequently confirmed, including elective surgical patients, patients with cardiovascular disease and infants on intensive care unit [20-22]. Current recommendations and guidelines regarding erythrocyte transfusion can be summarized, red cell transfusion is always indicated when $\mathrm{cHb}$ is $<6.0 \mathrm{~g} / \mathrm{l}$, and never when $\mathrm{cHb}$ is $\geq 10.0$ $\mathrm{g} / \mathrm{dl}[23]$.

These data suggest, that many if not most red cell transfusions are administered with debatable indication.

\section{Preoperative Anemia}

There is also concern about anemic patients in the preoperative period. Dunne and coworkers in patients with colonic cancer and patients with hip fractures as well as $\mathrm{Wu}$ and coworkers in patients $>65$ years old with noncardiac surgery reported the negative impact of preoperative anemia on relevant outcome characteristics including hospital mortality [24,25]. All these research groups concluded that associated co-morbidity rather than preoperative anemia alone may have led to a poorer outcome. They recommend the correction of anemia prior to surgery with iron, folate and vitamin B supplementation and the administration of erythropoietin.

\section{Preoperative Anemia as an Independent Risk Factor}

There are some studies where the authors tie themselves down to the conclusion that preoperative anemia is an independent risk factor for deteriorating patients' outcome [26,27]. Discussing the particular issue we have to consider the common reader's increasing difficulties to comprehend published medical information. The difficulties are

1. To understand the adequacy of the methods including statistics

2. To interpret the results and

3. To be able to relate to the authors' conclusions.

One large study may be exemplary for these problems. In 2011 Musallam et al. published a retrospective cohort study about the influence of preoperative hematocrit (hct) on postoperative outcome, using the database from the American College of Surgeons National Surgical Quality Improvement Program [26]. Altogether 227,425 patients during 2008 with non-cardiac surgery were included. The authors defined two levels of preoperative anemia, 'mild' as hct $>29$ - $<36 \%$ (women) and 39\% (men) resp., 'moderate-to-severe' as hct $\leq$ $29 \%$. They created separate multivariate logistic regression models for 30-day mortality and composite morbidity adjusting the preoperative hematocrit to potential clinical confounders. The statistics applied included separate sensitivity analysis of 34,905 excluded cases, which had no documented preoperative hct values. Their results (Figure 2) demonstrate preoperative anemia being an independent risk factor for patients' outcome, with an increase of mortality from $0.78 \%$ (no anemia) to $3.52 \%$ (mild anemia) to $10.17 \%$ (moderate-to-severe anemia). The authors state, 'Preoperative anemia, even to a mild degree, is independently associated with an increased risk of 30-day mortality and morbidity in patients undergoing major noncardiac surgery'. They suggest at least in elective cases to treat anemia with iron, vitamins and erythropoietin before surgery, asking for further studies evaluating a cost/benefit ratio for this strategy. The sponsor of Musallams study, Vifor Pharma, is the world's largest producer of intravenous iron. The 


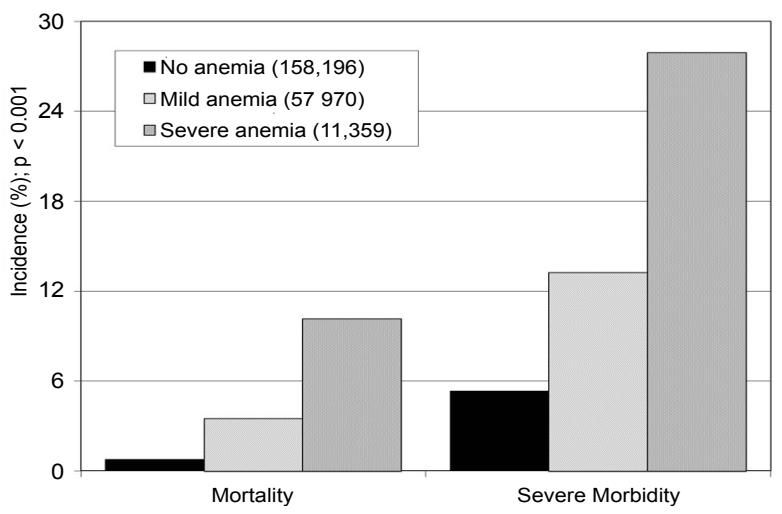

Figure 2: Mortality and morbidity of non-cardiac surgical patients (number in brackets) related to preoperative hematocrit (hct): No anemia $=$ hct $\geq 39 \%$; mild anemia $=$ hct $>29-<36($ women $) /<39 \%$ (men); severe anemia $\leq 29 \%$ Musallam et al. [26].

employer of one co-author, Novartis-Sandoz, was in 2011 involved in developing the generic 'epoetin alfa', a recombined erythropoietin used to treat anemia. We state expressively that we do not assume the authors intended to promote any pharmaceutical products. On the other hand no drug company supports research projects without expecting benefits for their business. Taking the results and the conclusions of this study seriously, physicians are in a dilemma. Treating anemia means either transfusion which may even worsen the patients' situation, or conservative treatment with iron, vitamins and erythropoietin leading to a significant delay of surgery that is not acceptable for many patients, particularly those with cancer. Additionally the effect of iron therapy on perioperative anemia is not sufficiently documented yet, [28] and the administration of erythropoietin is expensive, costs that have to be repaid by the patient in most countries. Though we appreciate the great effort of Musallam et al. we cannot follow their drift when it comes to interpreting their results. Their conclusion that preoperative anemia is an independent risk factor for postoperative outcome contradicts clinical observations and is not backed by any physiological data.

\section{Preoperative Anemia is a Symptom}

Musallam et al. substantiate their conclusions with the large number of patients and an outstanding statistical effort [26]. Our difficulties of comprehension start with the term 'anemia', as we consider neither a hematocrit $<36$ and $<39 \%$ resp. nor $\leq 29 \%$ as clinical relevant anemia. Within Musallams discussion, dealing extensively with statistical aspects we miss any pathophysiological consideration why preoperative anemia may lead to impaired postoperative outcome in otherwise adequately treated patients. Anemia even in its 'moderate-to-severe' form (hct $\leq 29 \%$ ) provides more than double of the oxygen needed by the tissues (Table 1). Furthermore the exclusion of co-morbidity and perioperative transfusion rates $2.52 \%, 10.49 \%$, and $35.88 \%$ respectively in 'non-', 'mild'-, 'moderate to severe'-anemia patients as confounding factors by the authors is inexplicable, even if statistic rules may allow such 'acrobatic'.

Some of the studies about deterioration of surgical patients' outcome after red cell transfusion used the identical database as Musallam. Two of them, Ferraris et al. and Glance et al. included noncardiac patients with preoperative anemia, comparable to Musallams classification [11,12]. Both Ferraris ('mild' anemia) and Glance ('severe' anemia) when compared to Musallam had similar or bigger groups, less transfusions and consequently lower mortality rates: 1.19 vs. $3.52 \%$ and
4.73 vs. $10.17 \%$ respectively. The fact that their data are not at all in accordance with Musallam et al. (Table 2) though using the identical database, leaves the reader clueless.

This apparent confusion teaches us an important lesson. The 'outcome' of scientific research is anything but exclusively related to design and methods, but also to the research question. Studies, such as Musallam et al., Ferraris et al. and Glance et al. are based on formidable large amounts of data, prospectively collected by $173,>200$ and 211 resp different hospitals with non-standardized diagnostic and therapeutic procedures $[11,12,26]$. Bearing this in mind, under certain circumstances even a small single center study may compete with them. In the mentioned study of Senay et al. about cardiosurgical patients, the group with a nadir hematocrit of $<21 \%$ during ECC had a mean initial hematocrit of $36 \%$, which is a 'mild anemia' following Musallams classification. The mortality rate of these patients was $0 \%$, compared to $3.52 \%$ (Musallam) and 1.19\% (Ferraris) respectively $[7,11,26]$.

Considering the current literature we rate preoperative anemia as an important surrogate parameter for patients' general condition, affecting the perioperative course. We don't find yet any comprehensible pathophysiologic explanation why preoperative anemia should exclusively have an impact on postoperative morbidity and mortality, and why its effect on patients' outcome should be different to intra- and postoperative anemia $[1,6,12,21]$.

\section{Statistics-Blessing or Curse?}

The demonstrated contradictions may be due to data selection and different statistical approaches. We assume many readers of scientific articles, even if they are experts in the medical issue are no longer able to cope with the variety of sophisticated and complicated statistics, thus being dependent on authors' and editors' competence and reliability. However, believing in results and conclusions of impressing studies in high ranking journals, even if they are contrary to their own experience, many physicians will reconsider and change therapeutic strategies, possibly falsely.

The Greek statistician John Ioannidis is one of the world's foremost experts on the credibility of medical research. He claims that the vast majority of the published medical information that doctors rely on is flawed [29]. The fact that his work broadly targets everyone else's work in medicine, as well as everything that physicians do and the health advice we get, Ioannidis may be one of the most influential scientists alive. Yet for all his influence, he worries that the field of medical research is so riddled with conflicts of interest that it might be chronically resistant to change. His conclusions have been strictly opposed by Jager and Leek estimating after all a $14 \%$, thus 'tolerable' rate of false information [30]. However their analysis only included less than $4 \%$ of the papers published and only the five highest ranked

\begin{tabular}{|c|c|c|c|c|}
\hline & \multicolumn{2}{|c|}{ 'Mild' Anemia } & \multicolumn{2}{c|}{$\begin{array}{c}\text { 'Severe-to-moderate' } \\
\text { Anemia }\end{array}$} \\
\hline Author & Musallam 2011 & Ferraris 2012[11] & $\begin{array}{c}\text { Musallam } \\
\mathbf{2 0 1 1}\end{array}$ & $\begin{array}{c}\text { Glance } \\
\text { 2011[12] }\end{array}$ \\
\hline $\begin{array}{c}\text { Preoperative } \\
\text { Hematocrit (\%) }\end{array}$ & $>29-<36 / 39$ & 34.85 (mean) & $\leq 29$ & $<28$ \\
\hline $\mathbf{n}$ & 57,870 & 908,391 & 11,359 & 10,100 \\
\hline $\begin{array}{c}\text { Perioperative } \\
\text { Transfusion (\%) }\end{array}$ & 10.49 & 1.67 & 35.88 & 21.0 \\
\hline Mortality (\%) & 3.52 & 1.19 & 10.17 & 4.73 \\
\hline
\end{tabular}

Table 2: Outcome and transfusion rate in surgical patients with 'mild' and 'moderate to severe' preoperative anemia, following the classification of Musallam et al. [26]. 
Citation: Suksompong S, Bormann BV (2014) Does Preoperative Anemia Deteriorate Patients' Postoperative Outcome or about the Difficulty of Comprehension. J Blood Disorders Transf 5: 205. doi: 10.4172/2155-9864.1000205

Page 4 of 4

medical Journals. In his reply Ioannidis insists that, 'sadly', wrong methods and unreliable data are the rule in medical literature [31]. He acknowledges that researchers supported by drug companies don't even have to manipulate data intentionally. Wasn't it possible, he asked, that drug companies were carefully selecting the topics of the supported studies? "Maybe sometimes it's the questions that are biased, not the answers" he said.

This trip into the mysteries of statistics may demonstrate that we as practicing medical doctors are often dealing with an issue far beyond our expertise. However, even the most sophisticated study should neither blur our clinical experience nor paralyze our logical thinking.

\section{Conclusions}

We don't find any conclusive evidence that preoperative anemia alone deteriorates patients' outcomes; additionally there is no pathophysiological model to explain it. Instead, we believe that anemia is merely a symptom of concomitant morbidity leading to complications and death. Patients with preoperative anemia and major surgery have an above average rate of perioperative red cell transfusions, which is a proven independent risk factor for outcome deterioration.

Every effort should be done to avoid allogeneic red cell transfusion until it is really indicated. This includes maintaining normovolemia, permissive anemia, autologous transfusion, and professional blood management with the implementation of mandatory guidelines. The treatment of preoperative anemia in elective surgery is another option. However, it can be applied only to a small group of patients, due to limiting factors, such as time, costs and uncertain effect.

As a consequence of rapidly growing databases available to everybody there will be more and more large retrospective studies trying to answer various scientific questions. The more sophisticated research methods are applied, the more comprehensibility is needed for publishing results, following the suggestion of Leonardo da Vinci, "Simplicity is the ultimate sophistication".

\section{References}

1. Roberson RS, Bennett-Guerrero E (2012) Impact of red blood cell transfusion on global and regional measures of oxygenation. Mt Sinai J Med 79: 66-74.

2. Zander R, von Bormann B (1996) Life without hemoglobin. Anasthesiol Intensivmed Notfallmed Schmerzther 31: 488-490.

3. Weiskopf RB, Viele MK, Feiner J, Kelley S, Lieberman J, et al. (1998) Human cardiovascular and metabolic response to acute, severe isovolemic anemia. JAMA 279: 217-221.

4. Vaislic CD, Dalibon N, Ponzio O, Ba M, Jugan E, et al. (2012) Outcomes in cardiac surgery in 500 consecutive Jehovah's Witness patients: 21 year experience. J Cardiothorac Surg 7: 95.

5. Jo KI, Shin JW, Choi TY, Park YJ, Youm W, et al. (2013) Eight-year experience of bloodless surgery at a tertiary care hospital in Korea. Transfusion 53: 948-954.

6. von Bormann B (2007) [Clinical aspects of packed red cell transfusion. Lessons learned from Jehovah's Witnesses?]. Anaesthesist 56: 380-384

7. Senay S, Toraman F, Karabulut H, Alhan C (2009) Is it the patient or the physician who cannot tolerate anemia? A prospective analysis in 1854 nontransfused coronary artery surgery patients. Perfusion $24: 373-380$.

8. Bennett-Guerrero E, Zhao Y, O'Brien SM, Ferguson TB Jr, Peterson ED, et al. (2010) Variation in use of blood transfusion in coronary artery bypass graft surgery. JAMA 304: 1568-1575.

9. Dietrich KA, Conrad SA, Hebert CA, Levy GL, Romero MD (1990) Cardiovascular and metabolic response to red blood cell transfusion in critically ill volume-resuscitated nonsurgical patients. Crit Care Med 18: 940-944

10. Sadaka F, Aggu-Sher R, Krause K, O'Brien J, Armbrecht ES, et al. (2011) The effect of red blood cell transfusion on tissue oxygenation and microcirculation in severe septic patients. Ann Intensive Care 1: 46

11. Ferraris VA, Davenport DL, Saha SP, Austin PC, Zwischenberger JB (2012) Surgical outcomes and transfusion of minimal amounts of blood in the operating room. Arch Surg 147: 49-55.

12. Glance LG, Dick AW, Mukamel DB, Fleming FJ, Zollo RA, et al. (2011) Association between intraoperative blood transfusion and mortality and morbidity in patients undergoing noncardiac surgery. Anesthesiology 114: 283-292.

13. Murphy GJ, Reeves BC, Rogers CA, Rizvi SI, Culliford L, et al. (2007) Increased mortality, postoperative morbidity, and cost after red blood cell transfusion in patients having cardiac surgery. Circulation 116: 2544-2552.

14. Acheson AG, Brookes MJ, Spahn DR (2012) Effects of allogeneic red blood cell transfusions on clinical outcomes in patients undergoing colorectal cancer surgery: a systematic review and meta-analysis. Ann Surg 256: 235-244.

15. Marik PE, Corwin HL (2008) Efficacy of red blood cell transfusion in the critically ill: a systematic review of the literature. Crit Care Med 36: 2667-2674.

16. Paone G, Brewer R, Theurer PF, Bell GF, Cogan CM, et al. (2012) Preoperative predicted risk does not fully explain the association between red blood cell transfusion and mortality in coronary artery bypass grafting. J Thorac Cardiovasc Surg 143: 178-185.

17. Ghio M, Contini P, Negrini S, Mazzei C, Zocchi MR, et al. (2011) Down regulation of human natural killer cell-mediated cytolysis induced by blood transfusion: role of transforming growth factor-beta(1), soluble Fas ligand, and soluble Class I human leukocyte antigen. Transfusion 51: 1567-73.

18. Jackman RP, Utter GH, Muench MO, Heitman JW, Munz MM, et al. (2012) Distinct roles of trauma and transfusion in induction of immune modulation after injury. Transfusion 52: 2533-2550.

19. Hebert PC, Wells G, Blajchman MA, Marshall J, Martin C, et al. (1999) A multicenter, randomized, controlled clinical trial of transfusion requirements in critical care. Transfusion Requirements in Critical Care Investigators, Canadian Critical Care Trials Group. N Engl J Med 1340: 409-417.

20. Cooper HA, Rao SV, Greenberg MD, Rumsey MP, McKenzie M, et al. (2011) Conservative versus liberal red cell transfusion in acute myocardial infarction (the CRIT Randomized Pilot Study). Am J Cardiol 108: 1108-1111.

21. Carson JL, Terrin ML, Noveck H, Sanders DW, Chaitman BR, et al. (2011) Liberal or restrictive transfusion in high-risk patients after hip surgery. $\mathrm{N}$ Engl J Med 365: 2453-2462.

22. Lacroix J, Hébert PC, Hutchison JS, Hume HA, Tucci M, et al. (2007) Transfusion strategies for patients in pediatric intensive care units. $\mathrm{N}$ Engl Med 356: 1609-1619.

23. Retter A, Wyncoll D, Pearse R, Carson D, McKechnie S, et al. (2013) Guidelines on the management of anaemia and red cell transfusion in adult critically ill patients. Br J Haematol 160: 445-464

24. Dunne JR, Malone D, Tracy JK, Gannon C, Napolitano LM (2002) Perioperative anemia: an independent risk factor for infection, mortality, and resource utilization in surgery. J Surg Res 102: 237-244.

25. Wu WC, Schifftner TL, Henderson WG, Eaton CB, Poses RM, et al. (2007) Preoperative hematocrit levels and postoperative outcomes in older patients undergoing noncardiac surgery. JAMA 297: 2481-2488.

26. Musallam KM, Tamim HM, Richards T, Spahn DR, Rosendaal FR, et al. (2011) Preoperative anaemia and postoperative outcomes in non-cardiac surgery: retrospective cohort study. Lancet 378: 1396-1407.

27. Leichtle SW, Mouawad NJ, Lampman R, Singal B, Cleary RK (2011) Does preoperative anemia adversely affect colon and rectal surgery outcomes? J Am Coll Surg 212: 187-194.

28. Garrido-Martin P, Nassar-Mansur MI, Llana-Ducros R, Virgos-Aller TM, Rodriguez Fortunez PM, et al. (2012) The effect of intravenous and oral iron administration on perioperative anaemia and transfusion requirements in patients undergoing elective cardiac surgery: a randomized clinical trial. Interact. Cardiovasc Thorac Surg 15: 1013-1018.

29. Ioannidis JP (2005) Why most published research findings are false. PLoS Med 2: e124

30. Jager LR, Leek JT (2014) An estimate of the science-wise false discovery rate and application to the top medical literature. Biostatistics 15: 1-12.

31. Ioannidis JP (2014) Discussion: Why "An estimate of the science-wise false discovery rate and application to the top medical literature" is false. Biostatistic 15: 28-36. 